\title{
Photobiomodulation and myofascial temporomandibular disorder: Systematic review and meta-analysis followed by cost-effectiveness analysis
}

\author{
Ana-Paula-Taboada Sobral ${ }^{1}$, Sergio-de Sousa Sobral 1, Thalita-Molinos Campos ${ }^{1}$, Anna-Carolina-Ratto- \\ Tempestini Horliana ${ }^{1}$, Kristianne-Porta-Santos Fernandes ${ }^{1}$, Sandra-Kalil Bussadori ${ }^{1}$, Lara-Jansiski Motta ${ }^{1,2}$
}

\footnotetext{
${ }^{1}$ Postgraduate Program in Biophotonics Applied to Health Sciences, UNINOVE - São Paulo, Brazil

${ }^{2}$ Postgraduate Program
}

Correspondence:

Postgraduate Program in Biophotonics Applied to Health Sciences

Universidade Nove de Julho - UNINOVE

Rua Vergueiro, 235/249 - Liberdade

São Paulo-SP-Brazil -01504-000

larajmotta@terra.com.br

Sobral APT, Sobral SS, Campos TM, Horliana ACRT, Fernandes KPS, Bussadori SK, Motta LJ. Photobiomodulation and myofascial temporomandibular disorder: Systematic review and meta-analysis followed by

Received: 27/11/2020 cost-effectiveness analysis. J Clin Exp Dent. 2021;13(7):e724-32.

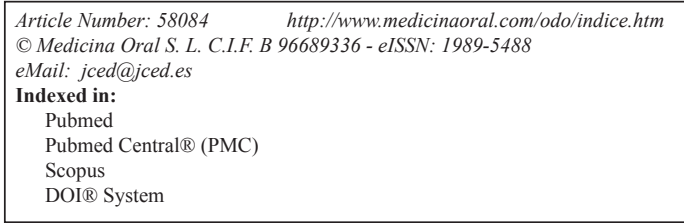

\begin{abstract}
Background: Photobiomodulation (PBM) is a non-invasive and non-pharmacological treatment, which, has shown beneficial results in the treatment of temporomandibular disorders (TMD) related pain. This systematic review and meta-analysis study aimed to evaluate the efficacy of photobiomodulation in the treatment of myofascial pain associated with (TMD by analyzing randomized clinical trials published from 2007 to February 2019. The secondary objective of the study was to perform a cost-effectiveness analysis of TMD treatment with photobiomodulation in patients with myofascial pain.

Material and Methods: International databases were used: Pubmed, Medline and Web of Science; the initial search raised 316 papers, and only 17 papers met the inclusion criteria for the systematic review (SR). Of these, only 04 papers met the inclusion criteria for meta-analysis: VAS data represented by numerical scores and placebo control group.

Results: As for the wavelength, the most used value was $780 \mathrm{~nm}$ (followed by $830 \mathrm{~nm}$. The most used treatment time was 4 offered treatments for 4 weeks; followed by 10 sessions. Regarding periodicity, 9 studies used 2 times a week. The meta-analysis showed that laser-treated groups had painful symptoms improvement that was superior to the control group (mean difference $1.49 ; 95 \% \mathrm{CI}=-1.67 ;-1.32$ ). Laser therapy showed a cost-effectiveness of $\$ 1,464.28$ by controlled pain intensity and placebo showed $\$ 2,866.20$ by controlled pain intensity.

Conclusions: The studies were considered to have moderate quality of evidence. Laser-treated groups had painful symptoms improvement that was superior to the control group and photobiomodulation was more cost-effective than placebo in patients with TMD and myofascial pain.
\end{abstract}

Key words: Temporomandibular disorder, Myofascial pain, Photobiomodulation, Placebo, Cost-effectiveness. 


\section{Introduction}

Temporomandibular disorder (TMD) is a term used to define clinical signs and symptoms affecting the masticatory muscles, the temporomandibular joint (TMJ) and associated structures (1-5). Among the most frequent signs and symptoms are masticatory muscle tenderness, pain in one or both TMJs, limited jaw movements, joint noise (5-7) and headache $(5,8,9)$. TMD signs and symptoms are found at all ages; however, the prevalence of this disorder, considered low in children, increases with age in adolescents and young adults $(10,11)$. Such disorders are a major cause of non-dental pain in the orofacial region, with $40 \%$ to $75 \%$ of nonpatient adult populations displaying at least one sign, and approximately $33 \%$ reporting at least one symptom of TMJ dysfunction (2). Among TMDs, the most common is myofascial pain, which causes pain and limited function, especially in chewing (4). Several resources, mainly for pain control, have been proposed for treatment such as occlusal splint, acupuncture, kinesiotherapy, massage therapy, postural training, psychotherapy, joint mobilizations, drug therapy, and laser therapy (12-13).

Low-level laser therapy (LLLT) or photobiomodulation $(\mathrm{PBM})$ is a non-invasive and non-pharmacological treatment, which, according to several studies, has shown beneficial results in the treatment of TMD-related pain. (3-6,13-21).

The therapeutic effects of LLLT on TMD include inflammatory modulator and analgesic effects $(4,5,7,21,22)$. Low-level lasers have demonstrated an ability to assist in the symptomatic treatment of pain, promoting a considerable degree of comfort to patients soon after its application. A major advantage of laser therapy for TMD is that it is a non-invasive, low-cost therapy and is currently widely used in dental practice, reducing the need for surgery or the use of drugs for pain relief and tissue regeneration. The use of laser therapy in patients with TMD has demonstrated pain relief minutes after application, promoting significant well-being. However, it is an adjunctive pain relief treatment due to the analgesic action of the laser which allows patients to resume their activities, providing them with greater convenience and better quality of life $(4,5,21,22)$.

The main objective of this systematic review and meta-analysis was to assess the efficacy of photobiomodulation in the treatment of myofascial TMD by analyzing randomized clinical studies published within the period from 2007 to February 2019. The secondary objective was to conduct a cost-effectiveness (CE) study based on the results of the meta-analysis.

\section{Material and Methods}

In order to maintain the methodological rigor of the systematic review and meta-analysis, the PRISMA (Preferred Reporting Items for Systematic Reviews and Me-
ta-Analyzes) guide was used to aid the process, offering guidance to improve the quality of data reporting (23). The systematic review protocol was registered in PROSPERO CRD42019131016.

-Search Strategy

Search strategy was conducted with the assistance of an expert medical librarian. A systematic search of the literature was conducted using sources, PubMed, Web of Science and MEDLINE, between 2007 and February 2019. The search was restricted to papers written in English and limited to randomized clinical studies whose treated patients had a diagnosis of temporomandibular disorder with myofascial pain.

-Selection of studies

An initial research using the keywords ("temporomandibular" OR "temporomandibular disorder" OR "temporomandibular joint" AND "temporomandibular joint" OR "low intensity laser therapy" OR "laser therapy" OR "photobiomodulation" OR "phototherapy" AND "myofascial pain"), in the databases (Pubmed, Medline and Web of Science) resulted in 316 studies. After reading the title and abstract, 17 papers that met the inclusion criteria were selected, as shown in Figure 1. The analysis was carried out by 2 trained reviewers and only randomized clinical studies were included, as they have higher level of evidence.

-Inclusion Criteria

First stage, two reviewers independently screened all the titles and abstracts identified by the electronic searches to identify the potentially relevant articles to be retrieved. Second stage, full-text copies of these studies were assessed by the same two reviewers for inclusion using the eligibility criteria according to PICO strategy. The research question was established based on the structured PICO, in the systematic review is question format was as follows: "What is the effectiveness of photobiomodulation in the treatment of TMD in patients with myofascial pain when compared to placebo?"

$\mathrm{P}$ (population): Patient Diagnosis of temporomandibular disorder with myofascial pain

I (Intervention): Laser therapy

C (Comparison): Placebo

O (Outcomes): Pain (VAS)

In order to obtain homogeneity among the selected studies for the meta-analysis to be carried out, only the works that used the VAS scale (Visual Analogue Scale) were selected to evaluate the interference result. For the meta-analysis, only studies that used the simulated placebo in the control group and that showed numerically arranged data were included.

-Data Extraction

A data extraction form was designed to enable data extraction relating to the study author and year of publication, country where the study was conducted, number of subjects, type of laser, radiant exposure $\left(\mathrm{J} / \mathrm{cm}^{2}\right)$, 

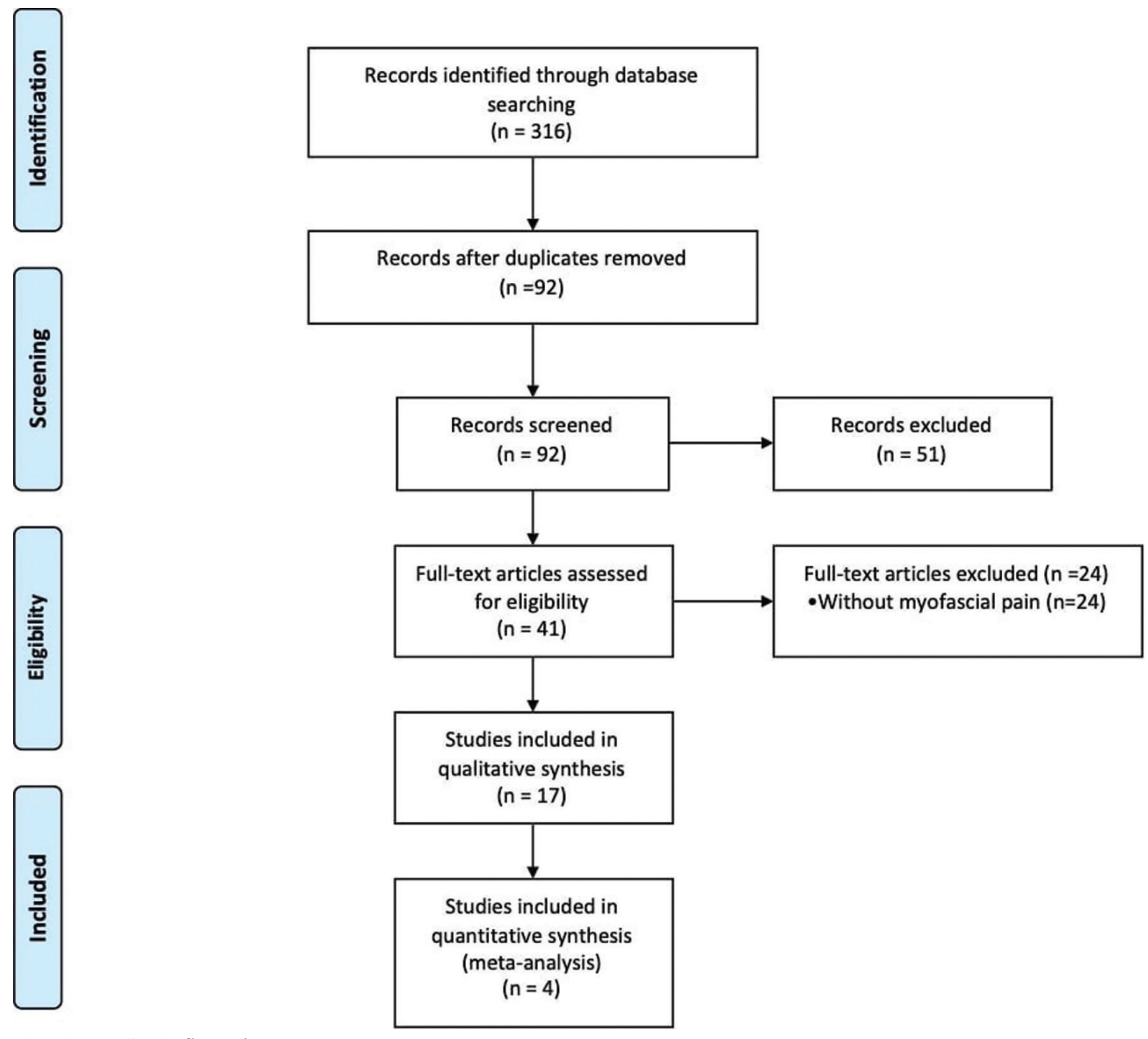

Fig. 1: PRISMA flow chart.

wavelength $(\mathrm{nm})$, power $(\mathrm{mW})$, treatment duration and frequency. Data extraction was performed by 1 reviewer and checked for accuracy by a second reviewer.

-Assessment of Risk of Bias

The risk of bias was assessed using the revised Cochrane risk of bias tool (RoB 2.0) in accordance with the study design of the included trials. Risk of bias assessment of the included studies was undertaken by one reviewer and checked for agreement by a second reviewer.

-Quality of Evidence

The quality of evidence for the primary outcomes was assessed using GRADE criteria. Evidence was classified as either very low, low, moderate, or high quality determined by risk of bias, inconsistency of results across studies, indirectness of available evidence, imprecision of results, and publication bias.

-Cost-Effectiveness Analysis

Cost-effectiveness establishes whether a treatment should be implemented as a therapeutic measure, being calculated by the difference between the cost of two interventions proposed as treatment divided by the difference between its consequences (effectiveness) (24).
-Cost Analysis

The cost of the visit (laser application session) was based on data presented by healthcare operators in Brazil and the treatment considered hospital costs in Brazil, following information from TUSS (Unified Terminology for Supplementary Health - Medical Procedures), with code and description: 31602215- LASER - PER SESSION (http://www.ans.gov.br/images/stories/Legislacao/in/anexo_in34_dides.pdf). An average of 2 sessions per week was considered, with 6 weeks of laser therapy, according to what was observed in the protocol by Sobral et al. (25).

In this research study, only direct medical costs were used, and the price of all materials used in the procedures was considered for calculation.

-Effectiveness Analysis

Treatment effectiveness in the systematic review followed by meta-analysis was measured by pain assessment using VAS data before and after treatment in the photobiomodulation and placebo groups.

-Data Analysis

The meta-analysis of relative risk was carried out based 
on the selected dichotomous results. Heterogeneity between the studies was calculated using I2 statistics and the analysis used the fixed effects model in this study. The results were described with the respective $95 \%$ confidence interval $(95 \% \mathrm{CI})$. Calculations were performed using the R software (The R Foundation for Statistical Computing, Austria). For all analyses, the level of significance was established as $\alpha=0.05$.

\section{Results}

-Systematic Review

-Characteristics of Included Studies

Papers were arranged in a table (Table 1), mentioning authors, country of the authors, year of publication, the number of patients who entered the study, the type of laser device, energy density, and the time and periodicity of treatment.

Table 1: Papers included in Systematic Review.

\begin{tabular}{|c|c|c|c|c|c|c|c|c|c|}
\hline Authors & Country & Year & $\begin{array}{c}\text { No. of } \\
\text { patients }\end{array}$ & $\begin{array}{l}\text { Laser } \\
\text { type }\end{array}$ & $\begin{array}{c}\text { Radiant } \\
\text { Exposure } \\
\left(\mathbf{J} / \mathbf{c m}^{2}\right)\end{array}$ & $\begin{array}{l}\text { Wave- } \\
\text { length } \\
(\mathrm{nm})\end{array}$ & $\begin{array}{l}\text { Power } \\
(\mathrm{mW})\end{array}$ & $\begin{array}{c}\text { Laser } \\
\text { therapy time }\end{array}$ & Periodicity \\
\hline $\begin{array}{l}\text { Magri LV et } \\
\text { al. } 2018(26)\end{array}$ & Brazil & 2018 & 41 & GaAlAs & $\begin{array}{c}\text { Masseter }=5 \\
\text { Temporal }=7.5\end{array}$ & 780 & $\begin{array}{l}\text { Masseter }=20 \\
\text { Temporal }=30\end{array}$ & $\begin{array}{l}4 \text { weeks }= \\
8 \text { sessions }\end{array}$ & $\begin{array}{l}\text { twice a } \\
\text { week }\end{array}$ \\
\hline $\begin{array}{l}\text { Borges, RMM } \\
\text { et al. } 2018 \text { (27) }\end{array}$ & Brazil & 2018 & 44 & AlGaAs & $\begin{array}{c}8 \\
60 \\
105\end{array}$ & 830 & 30 & $\begin{array}{l}3.5 \text { weeks }= \\
10 \text { sessions }\end{array}$ & $\begin{array}{l}3 \text { times a } \\
\text { week }\end{array}$ \\
\hline $\begin{array}{l}\text { Manfredini D } \\
\text { et al. } 2017 \text { (28) }\end{array}$ & Italy & 2018 & 30 & Lsl-GaAs & -------- & $\begin{array}{l}808 \\
905\end{array}$ & $\begin{array}{l}1.1 \\
25\end{array}$ & $\begin{array}{l}3 \text { weeks }= \\
9 \text { sessions }\end{array}$ & $\begin{array}{l}3 \text { times a } \\
\text { week }\end{array}$ \\
\hline $\begin{array}{l}\text { Magri LV et } \\
\text { al. 2017(29) }\end{array}$ & Brazil & 2017 & 91 & GaAlAs & $\begin{array}{l}\text { Masseter and } \\
\text { Temporal }=5 \\
\text { TMJ }=7.5\end{array}$ & 780 & $\begin{array}{l}20 \\
30\end{array}$ & $\begin{array}{l}8 \text { weeks }=16 \\
\text { sessions }\end{array}$ & $\begin{array}{l}\text { twice a } \\
\text { week }\end{array}$ \\
\hline $\begin{array}{l}\text { De Carli BM } \\
\text { et al. } 2016(30)\end{array}$ & Brazil & 2016 & --------- & Lsl-GaAs & 18 & 904 & --------- & --------- & --------- \\
\hline $\begin{array}{l}\text { Demirkol N et } \\
\text { al. } 2015(31)\end{array}$ & Turkey & 2015 & 30 & Nd:YAG & 8 & 1.064 & 250 & 10 days & Once a day \\
\hline $\begin{array}{l}\text { Rodrigues JH } \\
\text { et al. } 2015 \text { (32) }\end{array}$ & Brazil & 2015 & 10 & -------- & -------- & 780 & $\begin{array}{l}10 \\
70\end{array}$ & ------- & -------- \\
\hline $\begin{array}{l}\text { Leal de Godoy } \\
\text { CH et al. } 2015 \\
\text { (33) }\end{array}$ & Brazil & 2015 & 9 & GaAlAs & 33,5 & 786.94 & 50 & $\begin{array}{l}6 \text { weeks }=12 \\
\text { sessions }\end{array}$ & $\begin{array}{l}\text { twice a } \\
\text { week }\end{array}$ \\
\hline $\begin{array}{l}\text { de Moraes } \\
\text { Maia ML et al. } \\
2014 \text { (4) }\end{array}$ & Brazil & 2014 & 21 & GaAlAs & 70 & 808 & 100 & $\begin{array}{l}4 \text { weeks }=8 \\
\text { sessions }\end{array}$ & $\begin{array}{l}\text { twice a } \\
\text { week }\end{array}$ \\
\hline $\begin{array}{l}\text { Manca A et al. } \\
2014(34)\end{array}$ & Italy & 2014 & 60 & -------- & --------- & ------- & 30 & $\begin{array}{c}2 \text { weeks }=10 \\
\text { sessions }\end{array}$ & $\begin{array}{l}5 \text { times a } \\
\text { week }\end{array}$ \\
\hline $\begin{array}{l}\text { Uemoto L et } \\
\text { al. } 2013 \text { (35) }\end{array}$ & Brazil & 2013 & 21 & --------- & $\begin{array}{l}\text { Right Mas- } \\
\text { seter }=4 \text { Left } \\
\text { Masseter }=8\end{array}$ & 795 & 80 & 73 hours & $\begin{array}{l}48 \text { to } 72 \\
\text { hours }\end{array}$ \\
\hline $\begin{array}{l}\text { Ferreira LA et } \\
\text { al. } 2013(36)\end{array}$ & Brazil & 2013 & 38 & GaAlAs & 112,5 & 780 & 50 & $\begin{array}{c}4 \text { weeks }=8 \\
\text { sessions }\end{array}$ & $\begin{array}{l}\text { twice a } \\
\text { week }\end{array}$ \\
\hline $\begin{array}{l}\text { Venezian GC } \\
\text { et al. } 2010 \text { (13) }\end{array}$ & Brazil & 2010 & 48 & GaAlAs & $\begin{array}{l}25 \\
60\end{array}$ & 780 & $\begin{array}{l}50 \\
60\end{array}$ & $\begin{array}{c}4 \text { weeks }=8 \\
\text { sessions }\end{array}$ & $\begin{array}{l}\text { twice a } \\
\text { week }\end{array}$ \\
\hline $\begin{array}{l}\text { Öz S et al. } \\
2010 \text { (37) }\end{array}$ & Turkey & 2010 & 40 & $\begin{array}{l}\text { Laser } \\
\text { Diode }\end{array}$ & 3 & 820 & 300 & $\begin{array}{c}5 \text { weeks }=10 \\
\text { sessions }\end{array}$ & $\begin{array}{l}\text { twice a } \\
\text { week }\end{array}$ \\
\hline $\begin{array}{l}\text { Katsoulis et } \\
\text { al. } 2010(38)\end{array}$ & Switzerland & 2010 & 11 & -------- & $\begin{array}{l}40 \\
60\end{array}$ & 690 & 40 & $\begin{array}{l}3 \text { weeks }=6 \\
\text { sessions }\end{array}$ & $\begin{array}{l}\text { twice a } \\
\text { week }\end{array}$ \\
\hline $\begin{array}{l}\text { Carrasco TG } \\
\text { et al. } 2008(6)\end{array}$ & Brazil & 2009 & 60 & GaAlAs & $\begin{array}{c}25 \\
60 \\
105\end{array}$ & 780 & $\begin{array}{l}50 \\
60 \\
70\end{array}$ & $\begin{array}{c}4 \text { weeks }=8 \\
\text { sessions }\end{array}$ & $\begin{array}{l}\text { twice a } \\
\text { week }\end{array}$ \\
\hline $\begin{array}{l}\text { Fikácková H et } \\
\text { al. } 2007 \text { (14) }\end{array}$ & $\begin{array}{c}\text { Czech } \\
\text { Republic }\end{array}$ & 2007 & 61 & GaAlAs & $\begin{array}{l}0,1 \\
10 \\
15\end{array}$ & 830 & 400 & $\begin{array}{l}5 \text { weeks }=10 \\
\text { sessions }\end{array}$ & -------- \\
\hline
\end{tabular}


As observed in the studies included in this work, there is no consensus regarding radiant exposure. Out of the 17 studies, 2 used: $5 \mathrm{~J} / \mathrm{cm}^{2}$ (masseter) and $7.5 \mathrm{~J} / \mathrm{cm}^{2}$ (temporal) and 2 other studies, $25 \mathrm{~J} / \mathrm{cm}^{2}$ and $60 \mathrm{~J} / \mathrm{cm}^{2}$. As for the wavelength, the most used value was $780 \mathrm{~nm}(35.29 \%$ - 6 studies), followed by $830 \mathrm{~nm}$ (11.76\% - 2 studies). Based on the studies analyzed, the most used treatment time was 4 offered treatments for 4 weeks (4 studies); followed by 10 sessions, 3 studies. Regarding periodicity, 9 studies used 2 times a week.

\section{-Systematic Review - Risk of Bias}

When assessing the risk of bias in the studies, Table 2 and Figure 2 demonstrate the risk of bias in each study individually, for each domain considered in the risk assessment, using RoB 2.0 tool of the Cochrane collaboration.

-Meta-Analysis

The initial search resulted in 316 randomized clinical trials published from 2007 to February 2019, from which 17 papers were found and selected after evaluation by 2 reviewers, 4 of which met the inclusion criteria for meta-analysis: VAS data represented in numerical score and placebo control group.
-Quality of Evidence - GRADE

The papers included in this study underwent assessment as to the quality of evidence. Thus, according to the GRADE (Grading of Recommendations Assessment, Developing and Evaluation), Table 3 shows the quality of evidence for each study included.

It was observed that only 2 studies had a high degree of evidence quality, 1 had a moderate degree of evidence quality, and the other study had a low level of evidence quality. The studies were considered to have moderate and low quality of evidence because randomization and blinding were not well described and ensured in the methodology.

\section{-Effect of Low-Level Laser Therapy on TMD}

In total, with the 4 studies included in this meta-analysis Magri et al. (26), Demirkol et al. (31), de Moraes Maia et al. (4) and Magri et. al (29), this study evaluated 143 patients. According to Figure 3, we can see that 73 patients were in the laser group, while 70 were in the control group (placebo). These patients were further divided in terms of event, and effectiveness was measured by means of the difference in the absolute mean of VAS scores before and after treatment (1.49).

Table 2: Risk of individual bias in the seventeen studies selected for the systematic review, for each domain of risk assessment of bias in randomized clinical trials using the Cochrane collaboration tool.

\begin{tabular}{|c|c|c|c|c|c|c|}
\hline $\begin{array}{c}\text { Generation of } \\
\text { the random } \\
\text { sequence }\end{array}$ & $\begin{array}{c}\text { Assignment } \\
\text { concealment }\end{array}$ & $\begin{array}{c}\text { Blinding of } \\
\text { subjects and } \\
\text { professionals }\end{array}$ & $\begin{array}{c}\text { Blinding } \\
\text { of outcome } \\
\text { evaluators }\end{array}$ & $\begin{array}{c}\text { Incomplete } \\
\text { outcomes } \\
\text { (losses) }\end{array}$ & $\begin{array}{c}\text { Selective } \\
\text { outcome } \\
\text { report }\end{array}$ & $\begin{array}{c}\text { Other } \\
\text { biases }\end{array}$ \\
\hline Low & Low & Low & Low & Low & Low & Low \\
\hline High & High & High & High & Uncertain & Low & Low \\
\hline Uncertain & High & High & High & Uncertain & Low & Low \\
\hline Low & Uncertain & Uncertain & Uncertain & Low & Low & Low \\
\hline Uncertain & Uncertain & Uncertain & Uncertain & Low & Low & Low \\
\hline Low & Low & Low & Low & Uncertain & Low & Low \\
\hline Low & Low & Low & Low & Low & Low & Low \\
\hline Low & Low & Low & Low & Low & Low & Low \\
\hline Low & Uncertain & Uncertain & Uncertain & Low & Low & Low \\
\hline Uncertain & High & High & High & Low & Low & Low \\
\hline Low & Low & Low & Low & Low & Low & Low \\
\hline Low & Uncertain & High & High & Low & Low & Low \\
\hline High & High & High & High & Low & Low & Low \\
\hline Uncertain & High & High & High & Uncertain & Low & Low \\
\hline Uncertain & High & High & High & Uncertain & Low & Low \\
\hline Low & Low & Low & Low & Low & Low & Low \\
\hline Low & Low & Low & Uncertain & Low & Low \\
\hline
\end{tabular}




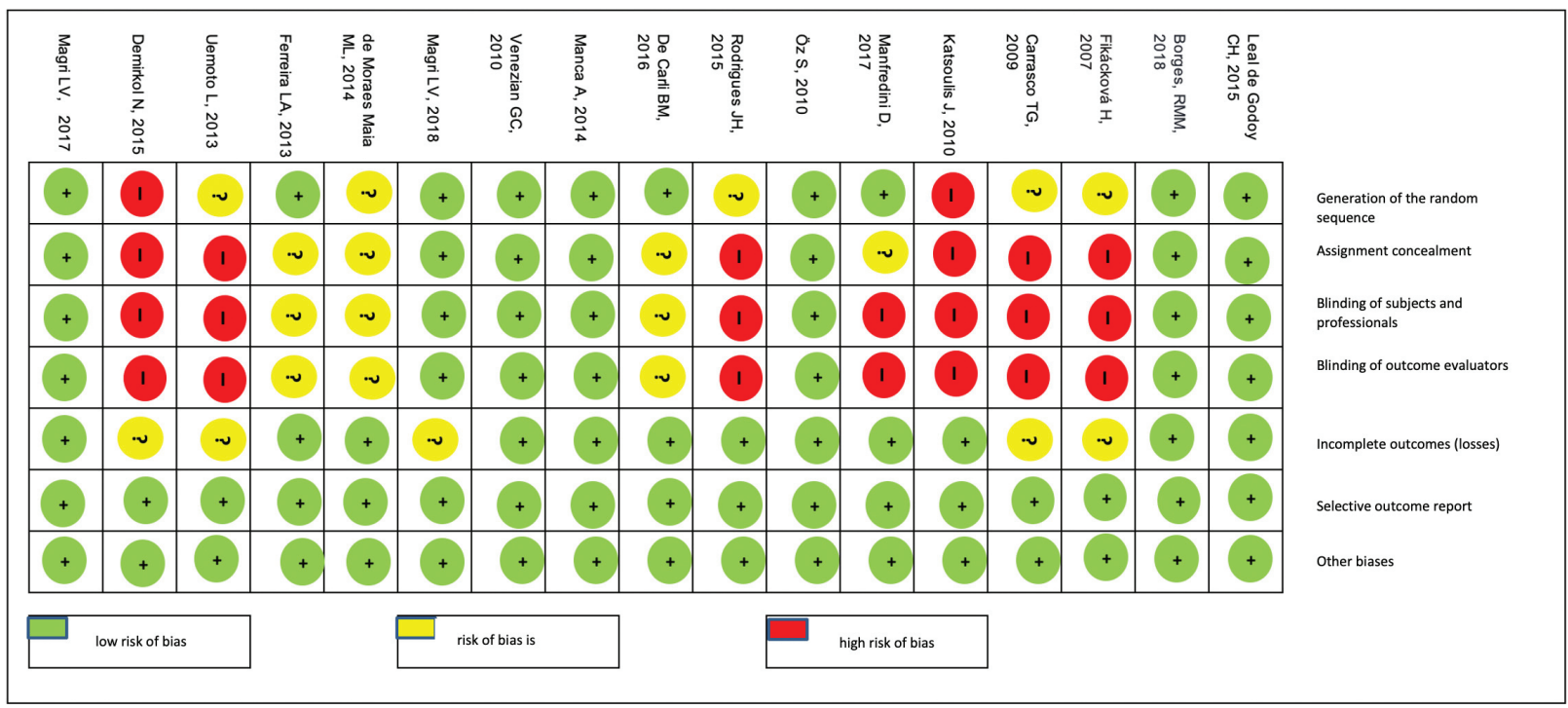

Fig. 2: Risk of individual bias.

Table 3: Evaluation of the Quality of Evidence from Studies.

\begin{tabular}{|l|l|}
\hline \multicolumn{1}{c|}{ Study / Author } \\
\hline $\begin{array}{l}\text { Effectiveness of low-level laser therapy on pain intensity, } \\
\text { pressure pain threshold, and SF-MPQ indexes of women } \\
\text { with myofascial pain (Magri, 2017) }\end{array}$ \\
\hline $\begin{array}{l}\text { Effectiveness of occlusal splints and low-level laser therapy } \\
\text { on myofascial pain (Demirkol, 2015) }\end{array}$ \\
$\begin{array}{l}\text { Evaluation of low-level laser therapy effectiveness on the } \\
\text { pain and masticatory performance of patients with } \\
\text { myofascial pain (De Morais Maia, 2014) }\end{array}$ \\
$\begin{array}{l}\text { Non-specific effects and clusters of women with painful } \\
\text { TMD responders and non-responders to LLLT: double- } \\
\text { blind randomized clinical trial. (Magri, 2018) }\end{array}$
\end{tabular}

\section{Study}

Magri et al. (2017)

Demirkol et al. (2015)

Maia et al.(2014)

Magri et al. (2018)

Fixed effect model

Random effects model

Heterogeneity: $I^{2}=98 \%, \tau^{2}=2.0851, p<0.01$

Fig. 3: Forest Plot with Data from Meta-Analysis Studies.

$31 \quad 2.00 \quad 0.4300$

$\begin{array}{lll}10 & 2.00 & 0.4700\end{array}$

$12 \quad 4.000 .5800$

$201.50 \quad 0.6100$

73

70

\section{Experimental Control}

$30 \quad 3.000 .4800$

$10 \quad 6.60 \quad 0.7300 \div$

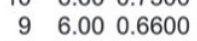

$21 \quad 2.500 .6900$

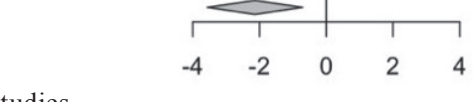

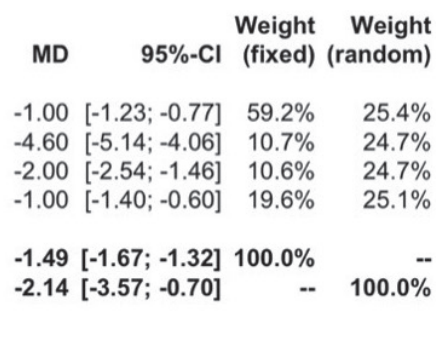


For this analysis, pain was considered as the outcome measure, being assessed by the visual analogue scale. The 4 studies were grouped for meta-analysis. The forest plot (Fig. 3) describes the weighted meta-analysis regarding pain intensity in patients with TMD. Significant heterogeneity was observed among the studies (I2 $=98 \% ; p<0.01)$ and a statistically significant difference was observed between the laser-treated group and the placebo group. The total mean difference was 1.49 (95\% CI $=-1.67 ;-1.32)$. The meta-analysis showed that laser-treated groups had painful symptoms improvement that was superior to the control group.

As for the mean difference analyzed separately for each study, the difference ranged from -1.00 to -4.60 on the pain scale. That is, in all studies it was possible to notice that the laser group shows a superior and statistically significant improvement in painful symptoms, which shows treatment effectiveness for cases of muscle pain in patients with TMD.

-Cost-Effectiveness

For the cost-effectiveness analysis, the value of 1.49 was considered as effectiveness, which represents the difference in the absolute mean of VAS scores before and after treatment (1.49) and the costs were calculated for a total of 12 sessions.

Table 4 describes the costs per patient and also per group within the sample, with the total cost of 12 sessions.

Table 4: Description of treatment costs in the laser and control groups.

\begin{tabular}{|l|c|c|}
\hline & $\begin{array}{c}\text { Laser group } \\
\text { (GL) }\end{array}$ & $\begin{array}{c}\text { Control Group } \\
\text { (GC) }\end{array}$ \\
\hline $\begin{array}{l}\text { Cost of 12 sessions* } \\
\text { Cycle per patient }\end{array}$ & $\$ 506.40$ & $\$ 506.40$ \\
\hline $\begin{array}{l}\text { Cost of 12 sessions* } \\
\text { Total N cycle }\end{array}$ & $\begin{array}{c}\$ 36.96 .20 \\
\mathrm{n}=73\end{array}$ & $\begin{array}{c}\$ 35,448.00 \\
\mathrm{n}=70\end{array}$ \\
\hline
\end{tabular}

The incremental cost of the Pain outcome in this study is $\$ 992.75$ per controlled pain intensity. The cost-effectiveness ratio for clinical treatment in the laser and placebo groups was $\$ 1,464.28$ and $\$ 2,866.20$ for controlled pain, respectively. The laser group being more cost-effective than the placebo group.

\section{Discussion}

The analyzed papers in RS indicate that low-level laser has been increasingly used to treat patients with myofascial TMD due to its analgesic, regenerative and anti-inflammatory effects and also due to the conservative characteristic of treatment. The survey also showed that no agreement has yet been reached regarding the parameters used in the treatments and, therefore, we do not have a defined protocol for the treatment of myofascial
TMD. This can make it difficult for the treatment to be standardized in public healthcare.

In addition, an aspect that made the analysis of the protocols used quite difficult is precisely because the authors did not provide all parameters for laser application. This occurred in 7 studies included in this study.

Of the 17 papers evaluated, we found a twice a week periodicity for laser therapy time in 10 studies, the minimum was 73 hours, and the maximum was 12 weeks. This study used the same periodicity and duration of treatment as the study by Leal de Godoy et al. (33).

The minimum parameter of $3 \mathrm{~J} / \mathrm{cm} 2$ has managed to show satisfactory results in improving pain and also in opening the mouth of patients with myofascial TMD (37).

According to what was possible to observe in this meta-analysis, all the studies analyzed showed that the laser-treated group had statistically superior improvement in painful symptoms when compared to the placebo group.

Ahrari et al. (18) conducted a randomized, double-blind clinical trial with 20 female patients who had myogenic TMD. The patients were divided into two groups, the laser group and placebo. As a result, it was observed that there was a significant reduction in pain symptoms in the laser group and a significant increase in the mouth opening parameter $(\mathrm{p}<0.05)$. Statistically significant improvement was not seen in the placebo group. Thus, the authors concluded that LLLT can provide significant improvements in the level of pain and mouth opening in patients with myogenic TMD. The relative risk made by the proportion of all studies included in the meta-analysis was 1.49 , using the fixed model, since the studies evaluated the same effect in different samples, through VAS. When assessing quality of evidence in the studies, only one study showed low quality, two showed high quality and one showed moderate quality of evidence. If we analyze the relative risk of each study, the works by Magri et al. $(26,29)$ were the ones with the lowest relative risk, 1.00 and their weights in the analysis were $59.2 \%$ and $19.6 \%$, being the highest weights in the study. The work by Demirkol et al. (31) showed the highest relative risk, 4.60 and its relative weight in the analysis was $10.7 \%$ when compared to the placebo group. But, for the relative risk, analyzing all the studies.

When the quality of the evidence from the studies was considered, the studies by Magri et al. $(26,29)$ showed high quality of evidence and that of Demirkol et al. (31) showed a low level of quality of evidence.

\section{Conclusions}

According to what was observed in the studies analyzed through systematic review and meta-analysis, laser therapy is effective when compared to placebo and more cost-effective in the treatment of myofascial TMD. 


\section{References}

1. Okeson JP, de Leeuw R. Differential diagnosis of temporomandibular disorders and other orofacial pain disorders. Dent Clin North Am. 2011;55:105-20.

2. Melis M, Di Giosia M, Zawawi KH. Low level laser therapy for the treatment of temporomandibular disorders: a systematic review of the literature. Cranio. 2012;30:304-12.

3. Maia ML, Bonjardim LR, Quintans Jde S, Ribeiro MA, Maia LG, Conti PC. Effect of low-level laser therapy on pain levels in patients with temporomandibular disorders: a systematic review. J Appl Oral Sci. 2012;20:594-602.

4. de Moraes Maia ML, Ribeiro MA, Maia LG, Stuginski-Barbosa J, Costa YM, Porporatti AL, Conti PC, et al. Evaluation of low-level laser therapy effectiveness on the pain and masticatory performance of patients with myofascial pain. Lasers Med Sci. 2014;29:29-35.

5. Dostalová T, Hlinakova $\mathrm{P}$, Kasparova M, Rehacek A, Vavrickova L, Navrátil L. Effectiveness of physiotherapy and GaAlAs laser in the management of temporomandibular joint disorders. Photomed Laser Surg. 2012;30:275-80.

6. Carrasco TG, Mazzetto MO, Mazzetto RG, Mestriner W Jr. Low intensity laser therapy in temporomandibular disorder: a phase II double-blind study. Cranio. 2008;26:274-81.

7. Cavalcanti MF, Silva UH, Leal-Junior EC, Lopes-Martins RA, Marcos RL, Pallotta RC, et al. Comparative Study of the Physiotherapeutic and Drug Protocol and Low-Level Laser Irradiation in the Treatment of Pain Associated with Temporomandibular Dysfunction. Photomed Laser Surg. 2016;34:652-6.

8. Marini I, Gatto MR, Bonetti GA. Effects of superpulsed low-level laser therapy on temporomandibular joint pain. Clin J Pain. 2010;26:611-6.

9. Torii K, Chiwata I. Occlusal adjustment using the bite plate-induced occlusal position as a reference position for temporomandibular disorders: a pilot study. Head Face Med. 2010;6-5.

10. Motta LJ, Guedes CC, De Santis TO, Fernandes KP, Mesquita-Ferrari RA, Bussadori SK. Association between parafunctional habits and signs and symptoms of temporomandibular dysfunction among adolescents. Oral Health Prev Dent. 2013;11:3-7.

11. Motta LJ, Martins MD, Fernandes KP, Mesquita-Ferrari RA, Biasotto-Gonzalez DA, Bussadori SK. Craniocervical posture and bruxism in children. Physiother Res Int. 2011;16:57-61

12. List T, Axelsson S. Management of TMD: evidence from systematic reviews and meta-analyses. J Oral Rehabil. 2010;37:430-51.

13. Venezian GC, da Silva MA, Mazzetto RG, Mazzetto MO. Low level laser effects on pain to palpation and electromyographic activity in TMD patients: a double-blind, randomized, placebo-controlled study. Cranio. 2010;28:84-91.

14. Fikácková H, Dostálová T, Navrátil L, Klaschka J. Effectiveness of low-level laser therapy in temporomandibular joint disorders: a placebo-controlled study. Photomed Laser Surg. 2007;25:297-303.

15. Emshoff R, Bösch R, Pümpel E, Schöning H, Strobl H. Low-level laser therapy for treatment of temporomandibular joint pain: a double-blind and placebo-controlled trial. Oral Surg Oral Med Oral Pathol Oral Radiol Endod. 2008;105:452-6.

16. Shirani AM, Gutknecht N, Taghizadeh M, Mir M. Low-level laser therapy and myofacial pain dysfunction syndrome: a randomized controlled clinical trial. Lasers Med Sci. 2009;24:715-20.

17. Mazzetto MO, Hotta TH, Pizzo RC. Measurements of jaw movements and TMJ pain intensity in patients treated with GaAlAs laser. Braz Dent J. 2010;21:356-60.

18. Ahrari F, Madani AS, Ghafouri ZS, Tunér J. The efficacy of low-level laser therapy for the treatment of myogenous temporomandibular joint disorder. Lasers Med Sci. 2014;29:551-7.

19. Melchior Mde O, Venezian GC, Machado BC, Borges RF, Mazzetto MO. Does low intensity laser therapy reduce pain and change orofacial myofunctional conditions? Cranio. 2013; 31:133-9.

20. Salmos-Brito JA, de Menezes RF, Teixeira CE, Gonzaga RK, Rodrigues BH, Braz R, Bessa-Nogueira RV, Gerbi ME. Evaluation of low-level laser therapy in patients with acute and chronic temporomandibular disorders. Lasers Med Sci. 2013;28:57-64.

21. Melchior MO, Machado BC, Magri LV, Mazzetto MO. Effect of speech-language therapy after low-level laser therapy in patients with TMD: a descriptive study. Codas. 2016;28:818-22.

22. Panhoca VH, Lizarelli Rde F, Nunez SC, Pizzo RC, Grecco C, Paolillo FR, Bagnato VS. Comparative clinical study of light analgesic effect on temporomandibular disorder (TMD) using red and infrared led therapy. Lasers Med Sci. 2015;30:815-22.

23. Moher D, Liberati A, Tetzlaff J, Altman DG; PRISMA Group. Reprint--preferred reporting items for systematic reviews and meta-analyses: the PRISMA statement. Phys Ther. 2009;89:873-80.

24. Moraz G, Garcez Ada S, de Assis EM, dos Santos JP, Barcellos NT, Kroeff LR. Estudos de custo-efetividade em saúde no Brasil: uma revisão sistemática [Cost-effectiveness in health in Brazil: a systematic review]. Cien Saude Colet. 2015;20:3211-29.

25. Sobral APT, Godoy CLH, Fernandes KPS, Bussadori SK, Ferrari RAM, Horliana ACRT, et al. Photomodulation in the treatment of chronic pain in patients with temporomandibular disorder: protocol for cost-effectiveness analysis. BMJ Open. 2018;8:e18326.

26. Magri LV, Carvalho VA, Rodrigues FCC, Bataglion C, Leite-Panissi CRA. Non-specific effects and clusters of women with painful TMD responders and non-responders to LLLT: double-blind randomized clinical trial. Lasers Med Sci. 2018;33:385-92.

27. Borges RMM, Cardoso DS, Flores BC, da Luz RD, Machado $\mathrm{CR}$, Cerveira GP, et al. Effects of different photobiomodulation dosimetries on temporomandibular dysfunction: a randomized, double-blind, placebo-controlled clinical trial. Lasers Med Sci. 2018;33:1859-1866.

28. Manfredini D, Favero L, Cocilovo F, Monici M, Guarda-Nardini L. A comparison trial between three treatment modalities for the management of myofascial pain of jaw muscles: A preliminary study. Cranio. 2018;36:327-331.

29. Magri LV, Carvalho VA, Rodrigues FC, Bataglion C, Leite-Panissi CR. Effectiveness of low-level laser therapy on pain intensity, pressure pain threshold, and SF-MPQ indexes of women with myofascial pain. Lasers Med Sci. 2017;32:419-428.

30. De Carli BM, Magro AK, Souza-Silva BN, Matos Fde S, De Carli JP, Paranhos LR, Magro ED. The effect of laser and botulinum toxin in the treatment of myofascial pain and mouth opening: A randomized clinical trial. J Photochem Photobiol B. 2016;159:120-3.

31. Demirkol N, Sari F, Bulbul M, Demirkol M, Simsek I, Usumez A. Effectiveness of occlusal splints and low-level laser therapy on myofascial pain. Lasers Med Sci. 2015;30:1007-12.

32. Rodrigues JH, Marques MM, Biasotto-Gonzalez DA, Moreira MS, Bussadori SK, Mesquita-Ferrari RA, et al. Evaluation of pain, jaw movements, and psychosocial factors in elderly individuals with temporomandibular disorder under laser phototherapy. Lasers Med Sci. 2015;30:953-9.

33. Leal de Godoy CH, Motta LJ, Santos Fernandes KP, Mesquita-Ferrari RA, Deana AM, Bussadori SK. Effect of low-level laser therapy on adolescents with temporomandibular disorder: a blind randomized controlled pilot study. J Oral Maxillofac Surg. 2015;73:622-9.

34. Manca A, Limonta E, Pilurzi G, Ginatempo F, De Natale ER, Mercante B, et al. Ultrasound and laser as stand-alone therapies for myofascial trigger points: a randomized, double-blind, placebo-controlled study. Physiother Res Int. 2014;19:166-75.

35. Uemoto L, Garcia MA, Gouvêa CV, Vilella OV, Alfaya TA. Laser therapy and needling in myofascial trigger point deactivation. J Oral Sci. 2013;55:175-81.

36. Ferreira LA, de Oliveira RG, Guimarães JP, Carvalho AC, De Paula MV. Laser acupuncture in patients with temporomandibular dysfunction: a randomized controlled trial. Lasers Med Sci. 2013;28:1549-58. 37. Öz S, Gökçen-Röhlig B, Saruhanoglu A, Tuncer EB. Management of myofascial pain: low-level laser therapy versus occlusal splints. J Craniofac Surg. 2010;21:1722-8.

38. Katsoulis J, Ausfeld-Hafter B, Windecker-Gétaz I, Katsoulis K, Blagojevic N, Mericske-Stern R. Laser acupuncture for myofascial 
pain of the masticatory muscles. A controlled pilot study. Schweiz Monatsschr Zahnmed. 2010;120:213-25.

\section{Author contribution}

Ana Paula Taboada Sobral: conceptualization, methodology, data curation; formal analysis; writing- original draft, writing- review \& editing; Sergio de Sousa Sobral: methodology, software, data curation; formal analysis; roles/writing-original draft; Thalita Molinos Campos: conceptualization, validation; roles/writing-original draft; Anna Carolina Ratto Tempestini Horliana: conceptualization, validation; roles/ writing-original draft; Kristianne Porta Santos Fernandes: methodology, formal analysis, data curation, writing - review \&editing; Sandra Kalil Bussadori: resources, methodology, software,writing - review \& editing; Lara Jansiski Motta: conceptualization, methodology, data curation; formal analysis; writing- review \& editing, supervision.

\section{Conflict of Interest}

The authors report no conflicts of interest related to this study. They did not receive any funding for this study. 